\title{
Cannabis use patterns at the dawn of US cannabis reform
}

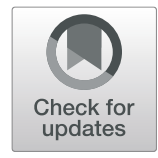

Navin Kumar ${ }^{1,2,3^{*}} \mathbb{D}$, Cheneal Puljević ${ }^{4}$, Jason Ferris ${ }^{4}$, Adam Winstock ${ }^{5,6}$ and Monica J. Barratt ${ }^{7,8,9}$

\begin{abstract}
In the United States (US), three in 10 cannabis users develop cannabis use disorder (CUD). Usage patterns in line with CUD may be associated with socio-economic disadvantage, and other negative effects. Thus, research on CUD is paramount. To provide understanding around CUD, it is necessary to detail granular cannabis usage preferences, as some risk from cannabis use may be mitigated through informed behavioral choices by users. We describe cannabis usage preferences among US Global Drug Survey (GDS) respondents, primarily young men. The crosssectional web-based GDS (2017) was completed by 8345 US-resident respondents (median age = 23, Interquartile Range 19-32; \% male $=75.48$ ) who reported cannabis use. Of those who reported cannabis use in the past year, most (78\%) reported consuming their first joint more than an hour after waking, and about half the sample (49\%) had their last joint 1-2 $\mathrm{h}$ before bed. Cannabis was used for a median of 250 days in the last year (almost daily). Respondents spent a median of four hours a day stoned when cannabis was used. High potency herbal cannabis was the preferred variant by $62 \%$ of participants. We suggest that frequent use of cannabis may increase risk of health harms, and highlight the need to mitigate problematic use. With the rapidly developing US cannabis market, possibly problematic usage patterns may indicate potential for CUD especially within young men.
\end{abstract}

Keywords: US legal Cannabis market, Cannabis preferences, Cannabis behaviors, Mode of consumption

\section{Introduction}

In the United States (US), three in 10 cannabis users develops cannabis use disorder (CUD) under DSM-IV guidelines (Hasin et al., 2015). When using DSM-5 guidelines, $19.5 \%$ of lifetime cannabis users met the criteria for CUD (Hasin et al., 2016). We define CUD as a problematic pattern of cannabis use leading to clinically significant impairment or distress as manifested by at least two of the markers of CUD, as defined by the DSM 5 (American Psychiatric Association, 2013). Usage patterns in line with CUD may be associated with socio-economic disadvantage, including unemployment or decreased financial stability (Brook et al., 2013). Research on CUD is paramount, to guide policy and interventions, especially with the rapid growth of US legal cannabis markets, given that states with legalized cannabis have greater rates of cannabis use and CUD (Cerdá et al., 2012). Cannabis may also provide some

\footnotetext{
* Correspondence: navin.kumar@yale.edu

${ }^{1}$ Yale Institute for Network Science, Yale University, New Haven, CT, USA

${ }^{2}$ Center for Empirical Research on Stratification and Inequality (CERSI), Yale

University, New Haven, CT, USA

Full list of author information is available at the end of the article
}

therapeutic benefits, for conditions such as multiple sclerosis and nausea (Grotenhermen \& Müller-Vahl, 2012; Zajicek et al., 2012). There are also recommendations for lower risk use, such as avoiding early initiation of use, and using low-potency products (Fischer et al., 2017). In this vein, some of the risk from cannabis use may be mitigated through informed behavioral choices by users (Fischer et al., 2017).

Thus, to provide understanding around CUD, it is necessary to detail cannabis usage preferences. However, there is a paucity of research exploring preferences around US cannabis use. Past work has explored demographic characteristics and cannabis use preferences, but these generally use data prior to rapid legalization in recent years (Carliner et al., 2017; Compton et al., 2016; Hasin et al., 2017; Terry-McElrath et al., 2017). More recent data is key as additional jurisdictions rapidly legalize medical and recreational cannabis use, and the possibly associated changes in CUD. Moreover, while these studies report cannabis prevalence, primarily utilizing the National Survey on Drug Use and Health (NSDUH), National Epidemiologic Survey on Alcohol

(C) The Author(s). 2019 Open Access This article is distributed under the terms of the Creative Commons Attribution 4.0 International License (http://creativecommons.org/licenses/by/4.0/), which permits unrestricted use, distribution, and 
and Related Conditions (NESARC), and Monitoring the Future (MTF), they do not indicate nuanced data on usage preferences, such as time of use and preferred cannabis variants (edibles, resin etc.). For example, given the sheer range of cannabis products (Hutmacher, 2015), charting prevalence of cannabis is not sufficient if users have preferences for different products and some are more likely to contribute to CUD compared to others (Loflin \& Earleywine, 2014). With the shifting US cannabis landscape, granular data on cannabis usage practices are key to pioneering policy and crafting future research. Using a USA-subset of a large cross-sectional online global survey, this paper describes a range of cannabis usage preferences, including time of first and last joint, quantities of use, and preferred forms of cannabis preparations. The survey questions we highlight are not in themselves the strongest markers of CUD, but understanding prevalence of cannabis use from a large sample may shed light on patterns of CUD.

\section{Methods}

The Global Drug Survey (GDS) annually conducts anonymous, online surveys to investigate international trends in drug use, both legal and illicit. Data from GDS 2017, collected from November 15, 2016 to January 18, 2017, is utilized in this paper. The age and sex distributions of cannabis users who completed the GDS in Australia, the US, and Switzerland were similar to their respective countries' demographic distributions in a household survey across the three countries (Barratt et al., 2017). When the GDS (2014) is compared to the similar NSDUH (2013) data, there are several key similarities. For example, regardless of age, men were more likely to report cannabis use compared to women. Both men and women typically demonstrate similar trends of a decreasing probability of lifetime and previous-year cannabis use with age. While the probability of ever using cannabis is greater in the GDS (2014) sample, the probability of using cannabis in the past year among lifetime users, and using within the past month among past-year users is comparable across GDS (2014) and NSDUH (2013) data. While non-response bias and volunteer bias may influence GDS samples, unmeasured confounders may affect data in household surveys (Keiding \& Louis, 2016). Household surveys may underestimate the prevalence of illicit drug use due to stigma and other factors (Chalmers et al., 2016; Zhao et al., 2009). In addition, GDS is far cheaper given its higher response rate, compared to household surveys (Barratt et al., 2017). For example, in GDS (2014), 6419 users were surveyed to recruit 3879 past-month cannabis users. In comparison, the NSDUH (2013) surveyed 43,465 to recruit 5664. Thus, the GDS is an effective way of gaining a nuanced understanding of stigmatized behaviors, if it is not used to estimate drug prevalence of the general population (Barratt et al., 2017). Sample representativeness may only be necessary when exploring research questions about population prevalence estimates (Barratt et al., 2017), and the GDS is thus appropriate to provide insight about US cannabis usage preferences within specific samples such as young males.

The survey was actively promoted on social media platforms, such as Twitter, Facebook, and through media partners, such as, Mixmag and The Guardian (USA). All respondents confirmed they were $16+$ years and provided informed consent. The study received institutional review board (IRB) approval from The Psychiatry, Nursing and Midwives Ethics subcommittee at Kings College, London (141/02), The University of Queensland (No: 2017001452) and The University of New South Wales (HREC HC17769). Analyses were first restricted to US-based respondents. Responses were included only if individuals indicated use of cannabis in the last 12 months, through all forms of administration, such as smoking, eating or vaporizing. The measures described in this paper include demographic characteristics, whether cannabis was mixed with tobacco in the last year, time of first joint, amount of cannabis used per session, number of hours of day spent stoned in a session, time of last joint, number of days cannabis was used in the last year, preferred form of cannabis in the last year, and most common method of administration.

Regarding mixing cannabis with tobacco, participants were asked whether they used tobacco mixed with cannabis in the last 12 months, with Never and Yes provided as response options. Concerning how soon after the participant woke up and had their first joint on the day they used cannabis, the selections of Immediately within $5 \mathrm{~min}$, Within less than an hour, Within 1-4h, Within 5-12 h and After more than $12 \mathrm{~h}$ were provided. For normal daily cannabis use, participants were asked to select the weight, from a dropdown list of 29 weights, starting at $50 \mathrm{mg}$ and gradually increasing to the final selection of $>20 \mathrm{~g}$. Regarding the number of hours spent stoned in a session, participants were asked to select from a dropdown list of 24 options, increasing in one-hour increments to the last option of 24 Hours. For the number of days cannabis was used in the last 12 months, participants keyed in their answer in a box provided. Participants were asked how long before bed they had their last joint, with the following options: Last thing before bed, $1-2 \mathrm{~h}$ before bed, 3-4 $\mathrm{h}$ before bed and More than $4 \mathrm{~h}$ before bed. Concerning the most common way participants used cannabis, the following options were provided: Smoked in a joint (rolled cannabis cigarette) with tobacco, Smoked in a joint without tobacco, Smoked in a blunt (cigar that has been hollowed out and filled with cannabis) with tobacco, Smoked in a blunt without tobacco, Smoked in a pipe with tobacco, Smoked in a pipe without tobacco, Smoked in a bong/water pipe with 
tobacco, Smoked in a bong/water pipe (filtration device generally used for smoking cannabis) without tobacco, Bucket bong (method of consuming smokable substances such as cannabis, using two containers), Hot knife (method of smoking cannabis with two knife blades), Vaporizer (device used to vaporize cannabis for inhalation), Eaten in food, Tincture/drank as tea, and Medical spray. For the preferred preparation of cannabis in the last year, participants could select the following: High potency herbal cannabis, Resin/hash (drug made from the resin of the cannabis plant), Normal weed/bush/pressed, Edibles (food product that contains cannabinoids), Kief (resinous trichomes of cannabis that may accumulate in containers), Oil, and Butane Hash Oil (oil extracted from cannabis using butane as a solvent). Prior to analysis, the variable regarding the time of first joint in a day was categorized into $>60$ mins and $<60$ mins of waking, to model time to first cigarette. The variable regarding the grams of cannabis used per session was recoded into a continuous variable, and the $>20 \mathrm{~g}$ value was recoded as $21 \mathrm{~g}$. On average, there are about $0.32 \mathrm{~g}$ of cannabis in a joint (Ridgeway \& Kilmer, 2016). For ease of interpretation, the age variable was recoded into a categorical variable with intervals of ten years each, and consecutive age groups representing less than $5 \%$ of the sample were subsumed into a larger group (41-79 years) for clearer interpretation.

\section{Results}

\section{Sample}

A total of 10,183 respondents from the US completed the survey between November 2016 and January 2017. Of these respondents, 8345 (82\%) participants reported cannabis use in the past year. There was missing data on some variables, and we have indicated the total number of cases for each variable (see Table 1). Males accounted for $75.48 \%$ of the sample, with a median age of 23 (interquartile range (IQR): 19-32, Range: $16-79$, see Table 1).

\section{Characteristics of Cannabis use}

Of those who reported cannabis use in the past year, most (78\%) reported consuming their first joint more than an hour after waking, and about half the sample had their last joint $1-2 \mathrm{~h}$ before bed (49\%) (see Table 1). The majority (78\%) tended not to mix tobacco with cannabis. Respondents reported using cannabis for a median of 250 days in the last year (almost daily), with $0.500 \mathrm{~g}$ the median per session. Respondents spent a median of four hours a day stoned when cannabis was used. Most (62\%) of respondents reported high potency herbal cannabis as their preferred cannabis preparation in the last year, followed by resin/hash (11\%). About a third (33\%) of participants smoked cannabis in a pipe without tobacco, followed by (23\%) smoking it in a bong/water pipe without tobacco.

\section{Discussion}

We sought to provide a descriptive report on cannabis use among a large sample of US-based survey respondents, largely young men, including time of first and last joint, mixing cannabis with tobacco, and other patterns of use. A low proportion of respondents used cannabis within the first hour of waking, suggesting limited preference for waking and baking (Earleywine et al., 2016) within young males. By avoiding waking and baking, young male cannabis users may possibly mitigate reductions in poor judgement later in the day, a common outcome when drugs are consumed earlier in the day (Earleywine et al., 2016). Factors that affect altered judgment are key for a demographic prone to risky behaviors (Iritani et al., 2007; Kuntsche et al., 2004). The high proportion of respondents stating time of last joint just before bed may indicate cannabis being used as a sleep aid. Thus, interventions to reduce problematic cannabis use may target young male users who indicate sleep issues as a symptom when purchasing legal cannabis. Most participants do not mix cannabis with tobacco, perhaps indicating an awareness of tobacco's harmful properties (Agrawal et al., 2009) within young men. Recent research has indicated the increasing use of electronic nicotine delivery systems (McMillen et al., 2012; Soneji et al., 2016), and perhaps such developments are associated with low levels of mixing cannabis with tobacco by young men. Most participants smoked cannabis in a pipe without tobacco. There is some evidence that this may not be the safest way to consume cannabis (Van Dam \& Earleywine, 2010). Nevertheless, consuming cannabis without tobacco may be safer than the less popular option of combining the product with tobacco (Meier \& Hatsukami, 2016), adding to research around lower risk use. Near daily cannabis use was reported by the majority of respondents, a possible health concern not in line with lower risk cannabis use (Fischer et al., 2017) and such patterns of use may be related to growing US cannabis markets. High potency herbal cannabis was the preferred variant, which may be less harmful compared to more potent, but less popular concentrates (Pierre et al., 2016; Raber et al., 2015). High potency herbal cannabis can contain up to $15 \%$ THC (Chan et al., 2017), but concentrates can have up to $40 \%$ THC content (ElSohly et al., 2016). The factors underpinning such a product preference may aid understandings around the long-term trajectory of US cannabis use, especially within young men. Several studies, primarily utilizing the NSDUH, NESARC and MTF report the prevalence of US cannabis use, CUD and frequency of use, along with demographic associations (Brook et al., 2013; Cerdá 
Table 1 Descriptive variables (number of participants reporting cannabis use in last year $=8345$ )

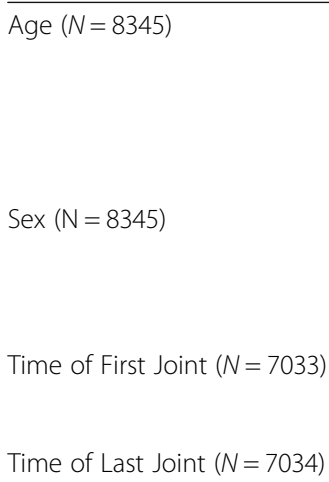

$\begin{array}{ll}-16-20 & 28.4 \% \\ -21-30 & 41.7 \% \\ -31-40 & 14.9 \% \\ -41-79 & 15.0 \%\end{array}$

-Male $\quad 75.5 \%$

-Female 23.6\%

-Transgender $\quad 0.9 \%$

$>60$ mins $\quad 78.0 \%$

$<60$ mins $\quad 22.0 \%$

-Last Thing before Bed $\quad 31.3 \%$

$-1-2 \mathrm{~h}$ before bed $\quad 49.1 \%$

$-3-4 \mathrm{~h}$ before bed $\quad 15.4 \%$

-More than $4 \mathrm{~h}$ before bed $\quad 4.2 \%$

No $\quad 78.0 \%$

Yes $22.0 \%$

Median $\quad 0.5$

Interquartile Range $\quad 0.125-1.000$

Median 4

Interquartile Range 3.0-6.0

Median 250

Interquartile Range $\quad$ 50-360

-High potency herbal cannabis $\quad 62.1 \%$

-Resin/hash $\quad 11.2 \%$

-Normal weed/bush/pressed $\quad 1.7 \%$

-Edibles $\quad 1.3 \%$

-Kief $\quad 8.3 \%$

-Oil $\quad 8.0 \%$

-Butane Hash Oil $\quad 7.6 \%$

-Smoked in a joint with tobacco $\quad 3.8 \%$

-Smoked in a joint without tobacco $\quad 11.3 \%$

-Smoked in a blunt with tobacco $\quad 0.7 \%$

-Smoked in a blunt without tobacco $\quad 7.5 \%$

-Smoked in a pipe with tobacco $\quad 0.5 \%$

-Smoked in a pipe without tobacco 33.3\%

-Smoked in a bong/water pipe with tobacco 2.6\%

-Smoked in a bong/water pipe without tobacco 23.0\%

-Bucket bong $\quad 1.5 \%$

-Hot knife $\quad 0.2 \%$

-Vaporizer $\quad 12.7 \%$

-Eaten in food $\quad 2.4 \%$

-Tincture/drank as tea $\quad 0.4 \%$

-Medical spray $\quad 0.1 \%$

et al., 2012; Earleywine et al., 2016; Hasin et al., 2016; Hasin et al., 2017; Hutmacher, 2015; Terry-McElrath et al., 2017). We extend their work by providing granular data around usage practices, such as cannabis product preferences and time of use, primarily in the young male demographic. Such nuanced data on usage preferences is 
key given the large range of cannabis products and modes of use. In addition, previous studies were conducted prior to the recent legalization of recreational cannabis in several states, and thus we extend past authors' work by providing recent data possibly more reflective of current practices.

\section{Limitations}

To the best of our knowledge, this study is the largest US-based study detailing cannabis use patterns. This research design has advantages and disadvantages, such as reliability and validity at a population-based level (Barratt et al., 2017; Winstock \& Barratt, 2013; Winstock et al., 2011). Online surveys are considered valid and useful when data are scarce, as with the current study. As hidden samples cannot be efficiently analyzed in generalized population-based surveys, comparable probability samples and ethnographic fieldwork may also be necessary to increase the external validity of our sample (Barratt et al., 2015). Also, as we used on online survey of drug users, our sample was skewed toward younger male participants, and may draw more regular cannabis users.

\section{Conclusion}

We provided data on US cannabis use patterns with largely young male participants, in the wake of rapid growing US legal cannabis markets. Overall, respondents engaged in less problematic modes of cannabis consumption, such as in a pipe without tobacco or in a bong without tobacco. However, the sample were stoned almost daily. High potency herbal cannabis was the preferred variant, which may be less harmful compared to more potent, but less popular concentrates. Frequent drug use may not be an issue in itself, but repeated use of any drug may increase risk of health harms, and thus we suggest that future research explore patterns of cannabis use in the changing US market.

\section{Abbreviations \\ GDS: Global drug survey; MTF: Monitoring the future; NESARC: National epidemiologic survey on alcohol and related conditions; NSDUH: National survey on drug use and health; US: United States}

\section{Acknowledgements}

The authors received no specific financial support for the research, authorship, and/or publication of this study. MJB and JAF were supported by fellowships from the Australian National Health and Medical Research Council (APP1070140, APP1089395). The National Drug and Alcohol Research Centre and the National Drug Research Institute were supported by funding from the Australian Government under the Substance Misuse Prevention and Service Improvement Grants Fund. We also acknowledge the contribution of the Victorian Operational Infrastructure Support Program received by the Burnet Institute.

Global Drug Survey is a self-funded organization; its media partners did not have any role in the design, interpretation or write-up of this paper. ARW is the founder and managing director of Global Drug Survey. We would like to thank the participants who gave so generously their time to complete the GDS. We are grateful for the promotion of GDS by a long list of world media partners, see Barratt et al. (2017). We are also indebted to Stuart Newman for his programming skills, advice and patience and Chris Parsons for his hard work in managing the translation site for the survey.

\section{Funding}

The authors received no specific financial support for the research, authorship, and/or publication of this study.

\section{Availability of data and materials}

The datasets used and/or analyzed during the current study are available from the corresponding author on reasonable request.

\section{Authors' contributions}

NK analyzed and interpreted the data. CP, JF, MB and AW were major contributors in writing the manuscript. All authors read and approved the final manuscript.

Ethics approval and consent to participate

All respondents confirmed they were $16+$ years and provided informed consent. The study received institutional review board (IRB) approval from The Psychiatry, Nursing and Midwives Ethics subcommittee at Kings College, London (141/02), The University of Queensland (No: 2017001452) and The University of New South Wales (HREC HC17769).

\section{Consent for publication}

NA

Competing interests

The authors declare that they have no competing interests.

\section{Publisher's Note}

Springer Nature remains neutral with regard to jurisdictional claims in published maps and institutional affiliations.

\section{Author details}

${ }^{1}$ Yale Institute for Network Science, Yale University, New Haven, CT, USA. ${ }^{2}$ Center for Empirical Research on Stratification and Inequality (CERSI), Yale University, New Haven, CT, USA. ${ }^{3}$ Department of Sociology, Yale University, New Haven, CT, USA. ${ }^{4}$ Centre for Health Service Research, University of Queensland, QLD, Brisbane, Australia. ${ }^{5}$ University College London, London, UK. ${ }^{6}$ Global Drug Survey Ltd, London, UK. ${ }^{7}$ Drug Policy Modelling Program, National Drug and Alcohol Research Centre, UNSW Sydney, Sydney, NSW, Australia. ${ }^{8}$ National Drug Research Institute, Faculty of Health Sciences, Curtin University, Perth, WA, Australia. ${ }^{9}$ Behaviours and Health Risks Program, Burnet Institute, Melbourne, VIC, Australia.

Received: 25 January 2019 Accepted: 7 April 2019

Published online: 07 June 2019

\section{References}

Agrawal A, Lynskey MT, Madden PA, Pergadia ML, Bucholz KK, Heath AC. Simultaneous cannabis and tobacco use and cannabis-related outcomes in young women. Drug Alcohol Depend. 2009;101:8-12.

American Psychiatric Association. Diagnostic and statistical manual of mental disorders (DSM-5 ${ }^{\circ}$ ): American Psychiatric Pub; 2013.

Barratt MJ, Ferris JA, Lenton S. Hidden populations, online purposive sampling, and external validity: taking off the blindfold. Field Methods. 2015;27:3-21.

Barratt MJ, Ferris JA, Zahnow R, Palamar JJ, Maier LJ, Winstock AR. Moving on from representativeness: testing the utility of the global drug survey. Subst Abuse Res Treat. 2017;2017:0-0.

Brook JS, Lee JY, Finch SJ, Seltzer N, Brook DW. Adult work commitment, financial stability, and social environment as related to trajectories of marijuana use beginning in adolescence. Subst Abuse. 2013;34:298-305. https://doi.org/10. 1080/08897077.2013.775092.

Carliner H, Brown QL, Sarvet AL, Hasin DS. Cannabis use, attitudes, and legal status in the US: a review. Prev Med. 2017;104:13-23.

Cerdá M, Wall M, Keyes KM, Galea S, Hasin D. Medical marijuana laws in 50 states: investigating the relationship between state legalization of medical marijuana and marijuana use, abuse and dependence. Drug Alcohol Depend. 2012;120:22-7.

Chalmers J, Lancaster K, Hughes C. The stigmatisation of 'ice'and under-reporting of meth/amphetamine use in general population surveys: a case study from Australia. Int J Drug Policy. 2016;36:15-24. 
Chan GCK, Hall W, Freeman TP, Ferris J, Kelly AB, Winstock A. User characteristics and effect profile of butane hash oil: an extremely high-potency cannabis concentrate. Drug Alcohol Depend. 2017;178:32-8. https://doi.org/10.1016/j. drugalcdep.2017.04.014.

Compton WM, Han B, Jones CM, Blanco C, Hughes A. Marijuana use and use disorders in adults in the USA, 2002-14: analysis of annual cross-sectional surveys. Lancet Psychiatry. 2016;3:954-64.

Earleywine M, Luba R, Slavin MN, Farmer S, Loflin M. Don't wake and bake: morning use predicts cannabis problems. Addict Res Theory. 2016;24:426-30.

EISohly MA, Mehmedic Z, Foster S, Gon C, Chandra S, Church JC. Changes in Cannabis potency over the last 2 decades (1995-2014): analysis of current data in the United States. Biol Psychiatry. 2016;79:613-9. https://doi.org/10. 1016/j.biopsych.2016.01.004

Fischer B, Russell C, Sabioni P, van den Brink W, Le Foll B, Hall W, Rehm J, Room R. Lower-risk Cannabis use guidelines: a comprehensive update of evidence and recommendations. Am J Public Health. 2017;107:e1-e12. https://doi.org/ 10.2105/AJPH.2017.303818.

Grotenhermen F, Müller-Vahl K. The therapeutic potential of Cannabis and cannabinoids. Dtsch Aerzteblatt Online. 2012. https://doi.org/10.3238/arztebl. 2012.0495 .

Hasin DS, Kerridge BT, Saha TD, Huang B, Pickering R, Smith SM, Jung J, Zhang $H_{\text {, }}$ Grant BF. Prevalence and correlates of DSM-5 cannabis use disorder, 20122013: findings from the National Epidemiologic Survey on alcohol and related conditions-III. Am J Psychiatry. 2016;173:588-99.

Hasin DS, Saha TD, Kerridge BT, Goldstein RB, Chou SP, Zhang H, Jung J, Pickering RP, Ruan WJ, Smith SM, Huang B, Grant BF. Prevalence of marijuana use disorders in the United States between 2001-2002 and 2012-2013. JAMA Psychiatry. 2015;72:1235. https://doi.org/10.1001/jamapsychiatry.2015.1858.

Hasin DS, Sarvet AL, Cerdá M, Keyes KM, Stohl M, Galea S, Wall MM. US adult illicit cannabis use, cannabis use disorder, and medical marijuana laws: 19911992 to 2012-2013. Jama Psychiatry. 2017;74:579-88.

Hutmacher A (2015) Beyond Flower - The Many Types of Marijuana. In: Colo. PotGuide. https://www.coloradopotguide.com/colorado-marijuana-blog/2015/ april/29/beyond-flower-the-many-types-of-marijuana/. Accessed 21 Feb 2019.

Iritani BJ, Hallfors DD, Bauer DJ. Crystal methamphetamine use among young adults in the USA. Addiction. 2007;102:1102-13. https://doi.org/10.1111/j. 1360-0443.2007.01847.x.

Keiding N, Louis TA. Perils and potentials of self-selected entry to epidemiological studies and surveys. J R Stat Soc Ser A Stat Soc. 2016;179:319-76.

Kuntsche E, Rehm J, Gmel G. Characteristics of binge drinkers in Europe. Soc Sci Med. 2004;59:113-27.

Loflin M, Earleywine M. A new method of cannabis ingestion: the dangers of dabs? Addict Behav. 2014;39:1430-3. https://doi.org/10.1016/j.addbeh.2014. 05.013 .

McMillen R, Maduka J, Winickoff J. Use of emerging tobacco products in the United States. J Environ Public Health. 2012;2012:1-8. https://doi.org/10.1155/ 2012/989474

Meier E, Hatsukami DK. A review of the additive health risk of cannabis and tobacco co-use. Drug Alcohol Depend. 2016;166:6-12.

Pierre JM, Gandal M, Son M. Cannabis-induced psychosis associated with high potency "wax dabs". Schizophr Res. 2016;172:211-2. https://doi.org/10.1016/j. schres.2016.01.056.

Raber JC, Elzinga S, Kaplan C. Understanding dabs: contamination concerns of cannabis concentrates and cannabinoid transfer during the act of dabbing. J Toxicol Sci. 2015:40:797-803. https://doi.org/10.2131/jts.40.797.

Ridgeway G, Kilmer B. Bayesian inference for the distribution of grams of marijuana in a joint. Drug Alcohol Depend. 2016;165:175-80. https://doi.org/ 10.1016/j.drugalcdep.2016.06.004.

Soneji S, Sargent J, Tanski S. Multiple tobacco product use among US adolescents and young adults. Tob Control. 2016;25:174-80. https://doi.org/ 10.1136/tobaccocontrol-2014-051638.

Terry-McElrath YM, O'Malley PM, Johnston LD, Bray BC, Patrick ME, Schulenberg JE. Longitudinal patterns of marijuana use across ages 18-50 in a US national sample: a descriptive examination of predictors and health correlates of repeated measures latent class membership. Drug Alcohol Depend. 2017;171:70-83.

Van Dam NT, Earleywine M. Pulmonary function in cannabis users: support for a clinical trial of the vaporizer. Int J Drug Policy. 2010;21:511-3.

Winstock AR, Barratt MJ. Synthetic cannabis: a comparison of patterns of use and effect profile with natural cannabis in a large global sample. Drug Alcohol Depend. 2013;131:106-11.
Winstock AR, Mitcheson LR, Deluca P, Davey Z, Corazza O, Schifano F. Mephedrone, new kid for the chop? Addiction. 2011:106:154-61.

Zajicek JP, Hobart JC, Slade A, Barnes D, Mattison PG, on behalf of the MUSEC Research Group. MUltiple sclerosis and extract of Cannabis: results of the MUSEC trial. J Neurol Neurosurg Psychiatry. 2012;83:1125-32. https://doi.org/ 10.1136/jnnp-2012-302468.

Zhao J, Stockwell T, MacDonald S. Non-response bias in alcohol and drug population surveys. Drug Alcohol Rev. 2009;28:648-57.

Ready to submit your research? Choose BMC and benefit from:

- fast, convenient online submission

- thorough peer review by experienced researchers in your field

- rapid publication on acceptance

- support for research data, including large and complex data types

- gold Open Access which fosters wider collaboration and increased citations

- maximum visibility for your research: over $100 \mathrm{M}$ website views per year

At BMC, research is always in progress.

Learn more biomedcentral.com/submissions 